\title{
Genetic structure of populations of Rhizoctonia solani AG-3 on potato in eastern North Carolina
}

\author{
Paulo C. Ceresini \\ Departamento de Biologia, Faculdade de Engenharia, \\ Universidade Estadual Paulista "Júlio de Mesquita \\ Filho" (UNESP), 15385-000, Ilha Solteira, São Paulo, \\ Brazil
}

H. David Shew

Department of Plant Pathology, North Carolina State University, Raleigh, North Carolina 27695

Rytas J. Vilgalys

Department of Biology, Duke University, Durham, North Carolina 27708

\section{U. Liane Rosewich} USDA-ARS, Cereal Disease Laboratory, University of Minnesota, Saint Paul, Minnesota 55108

Marc A. Cubeta ${ }^{1}$

Department of Plant Pathology, North Carolina State University, Raleigh, North Carolina 27695

\begin{abstract}
A polymerase chain reaction-restriction fragment length polymorphism (PCR-RFLP) method was developed to identify and differentiate genotypes of Rhizoctonia solani anastomosis group 3 subgroup PT (AG-3 PT), a fungal pathogen of potato. Polymorphic co-dominant single-locus PCR-RFLP markers were identified after sequencing of clones from a genomic library and digestion with restriction enzymes. Multilocus genotypes were determined by a combination of PCR product and digestion with a specific restriction enzyme for each of seven loci. A sample of 104 isolates from one commercial field in each of five counties in eastern North Carolina was analyzed, and evidence for high levels of gene flow between populations was revealed. When data were clone-corrected and samples pooled into one single North Carolina population, random associations of alleles were found for all loci or pairs of loci, indicating random mating. However, when all genotypes were analyzed, the observed genotypic diversity deviated from panmixia and alleles within and between loci were not randomly associated. These findings support a model of population structure for $R$. solani AG-3 PT on potato that includes both recombination and clonality.
\end{abstract}

\footnotetext{
Accepted for publication October 26, 2001.

${ }^{1}$ Corresponding author, Email: marc_cubeta@ncsu.edu
}

\author{
Key Words: migration, population subdivision, \\ Thanatephorus cucumeris
}

\section{INTRODUCTION}

The soilborne basidiomycete Rhizoctonia solani Kühn [Thanatephorus cucumeris (Frank) Donk] anastomosis group 3 subgroup PT (AG-3 PT) is a major pathogen infecting potato (Solanum tuberosum L.) worldwide. Symptoms and signs of Rhizoctonia disease of potato can be found on many plant parts including roots, sprouts, stems, stolons, and tubers. As potato plants reach maturity, the fungus can infest daughter tubers, producing black sclerotia on their surface (Carling et al 1989).

The ecology and pathology of $R$. solani AG-3 PT on potato has been extensively studied (Ogoshi 1987), but little information is available concerning the role of asexual and sexual reproduction in determining population structure of this important potato pathogen. In general, $R$. solani AG-3 PT is assumed to be asexual, surviving primarily as mycelium and sclerotia in soil and on potato seed tubers (Cubeta and Vilgalys 2000). However, the sexual stage (T. cucumeris) is frequently observed on potato stems in commercial production fields. Although basidiospores of T. cucumeris are assumed to have limited dispersal and little or no importance in the disease cycle (Carling et al 1989), they are an important aspect of fungal life history that contributes to the genetic diversity and structure of field populations. The mating system of $T$. cucumeris (anamorph $=R$. solani AG-3 PT) is not known. Likewise, it is not known whether recombination associated with sexual reproduction occurs among field isolates (Vilgalys and Cubeta 1994, Cubeta and Vilgalys 1997).

Except for the studies of Rosewich et al (1999), no information about the genetic diversity and structure of field populations of $R$. solani exists. Previous studies with $R$. solani AG-3 have employed various methods to examine the genetic variation among isolates from culture collections obtained from distinct Solanaceous hosts, including eggplant, potato, tobacco and tomato (Laroche et al 1992, Liu and Sinclair 1992, Liu et al 1993, Stevens Johnk et al 1993). However, basic questions remain about the population structure of $R$. solani AG-3 PT. For example: i) How 
diverse are populations of $R$. solani AG-3 PT from potato fields? and ii) Are populations of $R$. solani AG3 PT on potato clonal or panmictic?

In this study two null hypotheses were tested: a) populations of $R$. solani AG-3 PT from potato in North Carolina (NC) have no genetic subdivision or differentiation; and b) populations of $R$. solani AG-3 PT from potato plants are randomly mating (recombining). To address these hypotheses, a strategy for rapid detection of individual genotypes of $R$. solani AG-3 PT using co-dominant polymerase chain reaction (PCR)-RFLP markers was employed. These markers were used to assess the genetic diversity and structure of population samples of $R$. solani AG-3 PT obtained from one field from each of five different counties in NC. Analysis of genetic variation (e.g., similarity) and random mating among these samples were conducted. Data were also analyzed to determine whether populations of $R$. solani AG-3 PT were subdivided.

\section{MATERIALS AND METHODS}

Population sampling and DNA isolation.-Isolates of $R$. solani AG-3 PT for this study were obtained from infected subterranean potato stems with cankers. Infected plants were obtained from one commercial field in each of 5 counties in eastern NC (Ceresini 2000). Ten plots (2 per field), each consisting of 6-8 rows of $9 \mathrm{~m}$ length were planted with either 240 or 320 potato seed pieces (cv. 'Atlantic'). Seed potatoes used to establish the plots were disinfested before planting with $2 \%$ formaldehyde to eliminate seedborne $R$. solani AG-3 PT (Carling et al 1989). All plants from each plot were harvested and examined for symptoms of Rhizoctonia stem canker.

Samples were assayed on alkaline water agar (AWA, pH 8.5) to isolate $R$. solani AG-3 PT (Gutierrez et al 1997). A total of 104 pure cultures of $R$. solani were established by transferring mycelium from single hyphal tips to potato dextrose agar. Isolates were stored on sterilized rice grains at $-20 \mathrm{C}$. Isolates were examined for nuclear condition by the DAPI staining procedure (Martin 1987). The anastomosis grouping of each isolate of $R$. solani was determined by standard protocols (Gutierrez et al 1997, Herr and Roberts 1980). Genomic DNA was extracted by methods described previously (Rosewich et al 1999).

Development of PCR-RFLP markers.-Anonymous singlecopy DNA markers were developed using a strategy outlined by Karl and Avise (1993) and Xu et al (1999). A genomic library was constructed as described previously (Rosewich et al 1999) with Hind III-digested DNA of a randomly chosen NC isolate of $R$. solani AG-3 PT (P-211) cloned into pUC18 (Rosewich et al 1999). Sizes of clones resulting from this library were determined by digestion with Hind III and separation of DNA on a $0.8 \%$ agarose gel with a $1-\mathrm{kb}$ ladder. Clones with a single insert between 1 and $1.8 \mathrm{~kb}$ were selected (32 total). An extra clone with a $3.2 \mathrm{~kb}$ insert was also included in the sample. Both termini from 15 cloned DNA fragments were sequenced with forward and reverse primers for the multiple cloning site of pUC18 in an ABI Prism 377 automated sequencer (PE Applied Biosystems). Sequence chromatograms were compiled using Sequencher software (vers. 2.0, GeneCodes Corp.). Locus-specific PCR primers for 21-26 nucleotides were designed for further screening. PCR reactions were conduced in a Model 9600 DNA ThermoCycler (Perkin-Elmer) employing standard conditions described previously for $R$. solani (Vilgalys and Gonzalez 1990) with Amplitaq DNA polymerase (Perkin-Elmer). Restriction polymorphisms were detected initially by screening 21 random isolates of $R$. solani AG-3 PT from all five NC counties with restriction enzymes with 6-base recognition sites (Bam HI, Eco RI, Eco RV, Hind III, Hinc II, Hae II, Pst I, Sac I, Sty I, Xho I) or restriction enzymes with 4-base recognition sites (Hha I, Hae III, Mbo I, Msp I, Rsa I, Tru 9I). The entire sample of 104 isolates was then screened with combinations of PCR fragments and specific restriction enzymes that generated polymorphisms. Typical restriction enzyme reactions consisted of $5 \mu \mathrm{L}$ of PCR product, $7.5 \mathrm{U}$ of enzyme (Promega), $2.0 \mu \mathrm{L}$ of $10 \times$ reaction buffer, $0.2 \mu \mathrm{L}$ of $10 \times$ bovine serum albumin and $\mathrm{H}_{2} \mathrm{O}$ to a total volume of $20 \mu \mathrm{L}$. Reactions were incubated for $5 \mathrm{~h}$ at $37 \mathrm{C}$ (or according to manufacturer's recommendations) then stopped by incubation at $70 \mathrm{C}$ for $5 \mathrm{~min}$. Restriction digests of PCR products were separated by electrophoresis in 1.2 to $2.4 \%$ MetaPhor (FMC BioProducts) agarose gels in $1 \times \mathrm{TBE}$, containing ethidium bromide, and viewed by UV transillumination.

Data analysis.-Three data sets were constructed: (a) all isolates and retaining the five geographical populations (NC counties, uncorrected data); (b) clone-corrected data; isolates with the same multilocus PCR-RFLP genotype within each geographic population considered only once; and (c) either uncorrected or clone-corrected data of the combined isolates from all populations.

For analysis of genetic diversity within $R$. solani AG-3 PT populations, three population genetics measures were applied: (a) Stoddart's genotypic diversity (Stoddart and Taylor 1988) $G_{o}=1 /\left(\sum p_{i}^{2}\right)$, where $p_{i}$ is the frequency of a particular multilocus genotype, with $G_{o}$ ranging from 1 to $\mathrm{N}$, where $\mathrm{N}$ is the sample size. The sample-corrected genotypic diversity, $\mathrm{G}_{\mathrm{c}}=\mathrm{G}_{\mathrm{o}} / \mathrm{N}$, was used to allow comparisons between different populations. The expected overall genotypic diversity for a sample of size $\mathrm{N}$ was calculated using Stoddart's expected genotypic diversity (Stoddart 1983) $G_{E}$ $=1 /(d+p / N)$, where $d=\sum g_{\mathrm{i}}^{2}$ for all genotypes when $\left(g_{i}^{*} N\right) \geq 1$ and $p=\Sigma g_{\mathrm{i}}$ for all the genotypes when $\left.g_{i}^{*} N\right)$ $<1 ; g_{\mathrm{i}}$ is the expected frequency of the multilocus genotype calculated by Hardy-Weinberg expectations; (b) observed heterozygosity $\left(\mathrm{H}_{\mathrm{O}}\right)$ which represents the percentage of heterozygosity at each locus (Hartl and Clark 1997). The mean observed heterozygosity (i.e., gene diversity) was calculated as the arithmetic mean of all loci sampled; and (c) unbiased estimate of expected heterozygosity $\left(\hat{\mathrm{H}}_{\mathrm{E}}\right)$ or mean unbiased gene diversity, $\hat{\mathrm{H}}_{\mathrm{E}}=\sum_{k=1}^{r} \mathrm{~h}_{k} / r$, where $\mathrm{h}_{k}$ is the value of $\mathrm{h}$ for $k^{\text {th }}$ locus, and $\mathrm{r}$ is the total number of loci studied; $\mathrm{h}$ is an unbiased estimate of heterozygosity for a single locus 
TABLE I. Polymorphic PCR-RFLP markers for analysis of Rhizoctonia solani AG-3 PT from potato

\begin{tabular}{|c|c|c|c|c|c|c|}
\hline $\begin{array}{l}\text { PCR- } \\
\text { RFLP } \\
\text { locus }\end{array}$ & $\begin{array}{l}\text { Primer } \\
\text { code }\end{array}$ & Primer sequence $\left(5^{\prime}-3^{\prime}\right)$ & Length & $\begin{array}{l}\text { Fragment } \\
\text { size }^{\mathrm{a}}\end{array}$ & Enzyme & $\begin{array}{c}\text { Restriction } \\
\text { site }^{\mathrm{a}}\end{array}$ \\
\hline \multirow[t]{2}{*}{ pP09 } & F09 & TGTCAGTCGAGTTATCCGCGA & 21 & 530 & Hha I & 320 allele 1 \\
\hline & $\mathrm{R} 12$ & GATCAAGTGTATGCGCATGCG & 21 & & & 250 allele 2 \\
\hline \multirow[t]{2}{*}{$\mathrm{pP} 42$} & F12 & GTTTTTGTAGTGCACGGGGGT & 21 & 1970 allele 1 & Hind III & 1250 allele 2 \\
\hline & R09 & ATTCAACGTCTGTCGGTACGG & 21 & & & 1020 allele 3 \\
\hline \multirow[t]{2}{*}{$\mathrm{pP} 45$} & F09 & TTGTTCATCGTCCTCGAGTCTC & 22 & 965 allele 1 & Hind III & 765 allele 2 \\
\hline & R03 & ATCGGGTAAATTGCTACGCGA & 21 & & & \\
\hline \multirow[t]{2}{*}{$\mathrm{pP} 46$} & F09 & ATTAGCCCTGACTGGGTCTCG & 21 & 3050 allele 1 & Hind III & 2560 allele 2 \\
\hline & $\mathrm{R} 01$ & ACGATATTGCCTAGTGCGACC & 21 & & & \\
\hline \multirow[t]{2}{*}{$\mathrm{pP} 47$} & F08 & TTCATACCCAGATCGAGCGAC & 21 & 1960 & Eco RV & 1460 allele 1 \\
\hline & $\mathrm{R} 07$ & GCATATTTAATTTAGACAGGGACGC & 25 & & & 1190 allele 2 \\
\hline \multirow[t]{2}{*}{ pP83 } & F05 & TTGTGAACCTTACAAGTACCCGA & 23 & 1370 allele 1 & Hind III & 1000 allele 2 \\
\hline & R04 & AAGTATTATTCTCTGCGGTTCGC & 23 & & & 890 allele 3 \\
\hline \multirow[t]{2}{*}{ pP89 } & F02 & TTTGAGGAAGAACGCGTACGC & 21 & 1200 & $R s a \mathrm{I}$ & 660 allele 1 \\
\hline & $\mathrm{R} 10$ & TGTCATTGAAAATACGGCCGA & 21 & & & 515 allele 2 \\
\hline
\end{tabular}

a Size of PCR fragments are presented in base pairs.

given by $\mathrm{h}=2 n\left(1-\Sigma x_{i}^{2}\right) /(2 n-1)$, where $n$ is the number of diploid individuals, and $x_{i}$ is the corresponding frequency of the $i^{\text {th }}$ allele at a locus in a sample from the population (Levene 1949, Nei 1978, 1987). The expected heterozygosity was calculated with TFPGA version 1.3 (Miller 1997).

Between-population analyses were conducted to test for geographic structure in populations of $R$. solani AG-3 PT. Three population genetics analyses were performed: (a) analysis of molecular variance (AMOVA), which estimates variance components considering the number of differences between molecular genotypes (Weir and Cockerham 1984, Excoffier et al 1992, Weir 1996); (b) pairwise $\Phi$ statistics comparisons ( $\mathrm{F}$ statistics equivalents produced by AMOVA), which reveals similarity between the individual geographic populations. AMOVA analyses were conducted using ARLEQUIN ver 2.000 (Schneider et al 2000); and (c) similarity among the population samples calculated with $\mathrm{F}$ statistics (theta $\mathrm{P}$ or $\mathrm{F}_{\mathrm{WC}(\mathrm{ST})}$ as in Weir and Cockerham (1984)) and Nei's unbiased genetic distance (D) (Nei 1978, 1987). These tests $\left(\mathrm{F}_{\mathrm{WC}(\mathrm{ST})}\right.$ and $\left.\mathrm{D}\right)$, which are based on allele frequency differences between population samples, were calculated with GDA version 1.0 (d15) (Lewis and Zaykin 2000).

To compare the relative contribution of clonality and recombination in each sample of $R$. solani AG-3 PT, two population genetic measures were used: (a) the Hardy-Weinberg equilibrium (HWE) test, which examines the random association of alleles within a locus by testing the observed genotypic frequencies for goodness-of-fit with Hardy-Weinberg expectations (Hartl and Clark 1997) and (b) composite genotype disequilibrium or linkage disequilibrium (Weir 1996), which estimates the allelic association between pairs of polymorphic markers by an exact test for association through permutation (Zaykin et al 1995). To test for HWE, an exact test analogous to Fisher's exact test (Guo and Thompson 1992) was calculated with ARLEQUIN 2.000 (Schneider et al 2000). In addition, the likelihood ratio sta- tistic $G^{2}$ (recommended for genotypic data for which the haplotypic phase is unknown) was calculated with POPGENE (Yeh et al 1997). Linkage disequilibrium between all pairs of loci was calculated by an exact test analogous to Fisher's exact test (Slatkin 1994, Slatkin and Excoffier 1996). Calculations were performed with ARLEQUIN 2.000 (Schneider et al 2000).

\section{RESULTS}

Development of PCR-RFLP markers.-From the total of 32 randomly cloned Hind III-digested $R$. solani AG3 PT genomic DNA fragments selected based on size, 15 were partially sequenced and used to design locusspecific PCR primers. Eight fragments were found to be monomorphic, hypervariable or otherwise problematic (e.g., failing to amplify, producing multiple PCR fragments). The remaining seven DNA fragments could be re-amplified from all isolates and possessed unique restriction polymorphisms. Each of four fragments had one polymorphic restriction site, whereas three had two polymorphic sites. Each polymorphic restriction site, which corresponded to a unique combination of primer pair, restriction enzyme, and restriction site, was defined as a locus (TABLE I). Scoring by this method is unambiguous as each locus has potentially two alleles: allele 1 represents the absence of the restriction site, and allele 2 its presence. There were two cases where a third allele was present (i.e., markers pP42-Hind III and pP83-Hind III). When the restriction enzyme Hind III was used for digestion, allele 1 corresponded to the original (undigested PCR product) fragment size. However, for other restriction enzymes, allele 1 or 2 


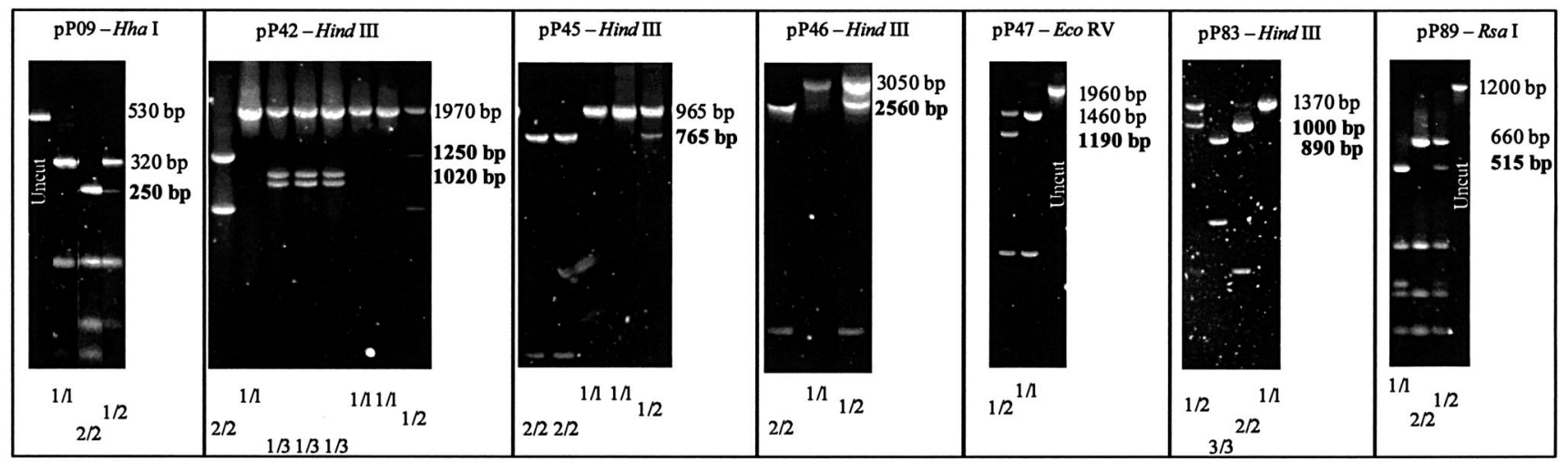

FIG. 1. PCR restriction fragment length polymorphisms (RFLPs) of Rhizoctonia solani AG-3 PT total DNA amplified with the locus-specific primers for pP09(F09/R12), pP42(F12/R09), pP45(F09/R03), pP46(F09/R01), pP47(F08/R07), pP83(F05/ R04), and pP89(F02/R10) markers showing homozygous (1/1, 2/2, and 3/3) and heterozygous (1/2) genotypes for each locus. The approximate size of each PCR fragment is presented in base pairs (bp) and was determined by comparing each migrating fragment with a DNA standard (either 100 or 1000 bp ladder, Promega). Polymorphic restriction sites for each locus are indicated in bold.

was smaller than the original fragment. Examples of the PCR-RFLP genotyping and allele designation methods are presented in FIG. 1.

Genotypic analysis.-Genotypes and genotypic counts for each of the five samples of Rhizoctonia solani AG$3 \mathrm{PT}$ are presented in TABLE II. Among the $104 R$. solani isolates analyzed, 32 multilocus PCR-RFLP genotypes (MRG) were identified. On average, 8.8 MRG were found per locality (range 2-15). Most of the MRG (about $81 \%$ ) were site specific (TABLES II AND III). However, isolates with the same genotype were also commonly observed between field sites. Five multilocus genotypes (MRG 3, 2, 1, 48 and 50) represented 13.5, 9.6, 8.7, 8.7, and $6.7 \%$ of the sample, respectively. Altogether, these five genotypes represented isolates, which accounted for $47.1 \%$ of the total population sample. The observed count of 14 for MRG 3, and 9 for either MRG 1 or MRG 48 was higher than the expected counts of 5.28 for both MRG 3 and MRG 1, and of 3.82 for MRG 48, which were derived under the hypothesis of panmixia (Stoddart and Taylor 1988). The observed and expected counts of genotypes for MRG 2 and 50 did not differ statistically.

As a control, a sample of the same potato seed tubers used for establishing the plots was subjected to isolation on AWA, before disinfestation with $2 \%$ formaldehyde. Six additional MRG were identified on these infested seed potatoes: one MRG $16(1 / 1$ $1 / 11 / 11 / 21 / 11 / 12 / 2)$, two MGR $17(1 / 11 / 1$ $1 / 1 \quad 1 / 21 / 1 \quad 1 / 22 / 2)$, one MRG $28(1 / 11 / 21 / 1$ $1 / 1 \quad 1 / 1 \quad 1 / 12 / 2)$, one MRG $37\left(\begin{array}{llll}1 / 1 & 1 / 2 & 1 / 1 & 2 / 2\end{array}\right.$ $1 / 1 \quad 2 / 2$ 2/2), one MRG $38\left(\begin{array}{llllll}1 / 1 & 1 / 2 & 1 / 2 & 1 / 1 & 1 / 1\end{array}\right.$ $1 / 12 / 2)$, and two MRG $59(1 / 21 / 11 / 21 / 11 / 1$
$1 / 11 / 2)$. No isolates of $R$. solani AG-3 PT were recovered from potato seed tubers after disinfestation.

Stoddart's genotypic diversity $\left(G_{o}\right)$ and the sample size-corrected genotypic diversity $\left(\mathrm{G}_{\mathrm{c}}\right)$ of $R$. solani AG-3 PT are presented in TABLE III. The mean genotypic diversity $\left(G_{c}\right)$ was 0.2945 . Overall, there was no difference between any pairs of samples considering their $G_{c}$ values. In addition, the observed overall genotypic diversity $\left(G_{0}\right.$ for uncorrected data $=$ 16.64) was smaller than the expected value under panmixia $\left(G_{E}^{*}=38.78\right)$ (TABLE II).

Gene diversity, patterns of heterozygosity and deviations from HWE.- Six of the seven loci surveyed from five geographical populations of $R$. solani AG-3 PT were polymorphic at all localities, with an average of 1.97 alleles per locus. The only exception was the locus pP45-Hind III, which was polymorphic only at Hyde County. Most alleles $(11 / 16)$ were present in all five populations. A rare allele was present at low frequencies in one population (allele 2 at locus pP45-Hind III in the population sample from Hyde).

The observed and expected heterozygosity of all samples from NC are presented in TABLE IV. Heterozygosity values varied greatly among loci, from 0.010 to 0.481 . Two of the seven loci had heterozygosity less than 0.100 ( $\mathrm{pP} 45-$ Hind III and pP47-Eco RV). The mean heterozygosity (over loci) of the samples was between 0.186 and 0.381 when all the isolates were included in the analysis and between 0.229 and 0.357 for clone-corrected data. Comparisons of mean heterozygosity of each sample indicated no difference between expected and observed values.

Each sample of $R$. solani AG-3 PT from NC was also examined for the association of alleles within a locus 
TABLE II. Frequency of multi-locus PCR-RFLP genotypes (MRG) of Rhizoctonia solani AG-3 PT from potato fields in North Carolina, and estimates of overall observed $\left(G_{\mathrm{O}}\right)$ and expected $\left(G_{E}^{*}\right)$ genotypic diversity

\begin{tabular}{|c|c|c|c|c|c|c|c|c|c|c|c|c|c|c|}
\hline \multirow[b]{3}{*}{$M R G^{\mathrm{a}}$} & \multirow{2}{*}{\multicolumn{7}{|c|}{ Genotype $^{\mathrm{b}}$}} & \multicolumn{5}{|c|}{$\begin{array}{l}\text { Frequency of MRG } \\
\text { in each county }\end{array}$} & \multirow{3}{*}{$\begin{array}{c}\text { Observed } \\
\text { count }^{\mathrm{d}}\end{array}$} & \multirow{3}{*}{$\begin{array}{l}\text { Expected } \\
\text { count }^{\mathrm{d}}\end{array}$} \\
\hline & & & & & & & & \multirow{2}{*}{$\begin{array}{c}\text { Wash- } \\
\text { ing- } \\
\text { ton }^{\mathrm{c}}\end{array}$} & \multicolumn{3}{|c|}{ Curri- } & \multirow{2}{*}{$\begin{array}{c}\text { Cam- } \\
\text { den }\end{array}$} & & \\
\hline & pP09 & pP42 & pP45 & $\mathrm{pP} 46$ & pP47 & pP83 & pP89 & & Tyrrell & tuck & Hyde & & & \\
\hline 1 & $1 / 1$ & $1 / 1$ & $1 / 1$ & $1 / 1$ & $1 / 1$ & $1 / 1$ & $1 / 1$ & & & 2 & 4 & 3 & 9 & 5.28 \\
\hline 2 & $1 / 1$ & $1 / 1$ & $1 / 1$ & $1 / 1$ & $1 / 1$ & $1 / 1$ & $1 / 2$ & & & & 3 & 7 & 10 & 10.66 \\
\hline 3 & $1 / 1$ & $1 / 1$ & $1 / 1$ & $1 / 1$ & $1 / 1$ & $1 / 1$ & $2 / 2$ & 5 & & & 7 & 2 & 14 & 5.28 \\
\hline 4 & $1 / 1$ & $1 / 1$ & $1 / 1$ & $1 / 1$ & $1 / 1$ & $1 / 2$ & $1 / 1$ & & & & & 1 & 1 & 1.13 \\
\hline 5 & $1 / 1$ & $1 / 1$ & $1 / 1$ & $1 / 1$ & $1 / 1$ & $1 / 2$ & $1 / 2$ & 1 & & & & 3 & 4 & 2.29 \\
\hline 6 & $1 / 1$ & $1 / 1$ & $1 / 1$ & $1 / 1$ & $1 / 1$ & $1 / 2$ & $2 / 2$ & & & & 2 & & 2 & 1.13 \\
\hline 7 & $1 / 1$ & $1 / 1$ & $1 / 1$ & $1 / 1$ & $1 / 1$ & $1 / 3$ & $2 / 2$ & & & & 1 & & 1 & 0.66 \\
\hline 12 & $1 / 1$ & $1 / 1$ & $1 / 1$ & $1 / 1$ & $1 / 2$ & $1 / 2$ & $2 / 2$ & & 1 & & & & 1 & 0.08 \\
\hline 14 & $1 / 1$ & $1 / 1$ & $1 / 1$ & $1 / 2$ & $1 / 1$ & $1 / 1$ & $1 / 1$ & & & & 1 & & 1 & 1.19 \\
\hline 15 & $1 / 1$ & $1 / 1$ & $1 / 1$ & $1 / 2$ & $1 / 1$ & $1 / 1$ & $1 / 2$ & & & & 1 & & 1 & 2.41 \\
\hline 20 & $1 / 1$ & $1 / 1$ & $1 / 2$ & $1 / 1$ & $1 / 1$ & $1 / 1$ & $1 / 2$ & & & & 1 & & 1 & 0.10 \\
\hline 26 & $1 / 1$ & $1 / 2$ & $1 / 1$ & $1 / 1$ & $1 / 1$ & $1 / 1$ & $1 / 1$ & & & & & 3 & 3 & 1.41 \\
\hline 27 & $1 / 1$ & $1 / 2$ & $1 / 1$ & $1 / 1$ & $1 / 1$ & $1 / 1$ & $1 / 2$ & 3 & & & & & 3 & 2.85 \\
\hline 29 & $1 / 1$ & $1 / 2$ & $1 / 1$ & $1 / 1$ & $1 / 2$ & $1 / 1$ & $1 / 2$ & & 1 & & & & 1 & 0.20 \\
\hline 34 & $1 / 1$ & $1 / 2$ & $1 / 1$ & $1 / 2$ & $1 / 1$ & $1 / 1$ & $1 / 2$ & & & & 2 & & 2 & 0.64 \\
\hline 36 & $1 / 1$ & $1 / 2$ & $1 / 1$ & $1 / 2$ & $1 / 2$ & $1 / 1$ & $1 / 2$ & & 1 & & & & 1 & 0.05 \\
\hline 42 & $1 / 1$ & $1 / 3$ & $1 / 1$ & $1 / 1$ & $1 / 1$ & $1 / 1$ & $1 / 1$ & & & & 1 & & 1 & 0.74 \\
\hline 43 & $1 / 1$ & $1 / 3$ & $1 / 1$ & $1 / 1$ & $1 / 1$ & $1 / 1$ & $1 / 2$ & & & & 2 & & 2 & 1.49 \\
\hline 45 & $1 / 1$ & $1 / 3$ & $1 / 1$ & $1 / 2$ & $1 / 1$ & $1 / 1$ & $2 / 2$ & 3 & & & & & 3 & 0.17 \\
\hline 48 & $1 / 2$ & $1 / 1$ & $1 / 1$ & $1 / 1$ & $1 / 1$ & $1 / 1$ & $1 / 1$ & 2 & 5 & & 1 & 1 & 9 & 3.82 \\
\hline 50 & $1 / 2$ & $1 / 1$ & $1 / 1$ & $1 / 1$ & $1 / 1$ & $1 / 1$ & $1 / 2$ & 1 & 5 & & 1 & & 7 & 7.72 \\
\hline 51 & $1 / 2$ & $1 / 1$ & $1 / 1$ & $1 / 1$ & $1 / 1$ & $1 / 2$ & $1 / 2$ & & & & & 1 & 1 & 1.66 \\
\hline 52 & $1 / 2$ & $1 / 1$ & $1 / 1$ & $1 / 1$ & $1 / 1$ & $1 / 3$ & $1 / 1$ & 2 & & & & 1 & 3 & 0.47 \\
\hline 54 & $1 / 2$ & $1 / 1$ & $1 / 1$ & $1 / 2$ & $1 / 1$ & $1 / 2$ & $1 / 2$ & & & & & 1 & 1 & 0.37 \\
\hline 55 & $1 / 2$ & $1 / 1$ & $1 / 1$ & $1 / 2$ & $1 / 1$ & $2 / 2$ & $1 / 2$ & & & & 3 & & 3 & 0.02 \\
\hline 56 & $1 / 2$ & $1 / 1$ & $1 / 1$ & $1 / 2$ & $1 / 1$ & $2 / 3$ & $1 / 2$ & & & & & 1 & 1 & 0.02 \\
\hline 63 & $1 / 2$ & $1 / 2$ & $1 / 1$ & $1 / 1$ & $1 / 1$ & $1 / 1$ & $2 / 2$ & & & & & 4 & 4 & 1.02 \\
\hline 66 & $1 / 2$ & $1 / 2$ & $1 / 1$ & $1 / 2$ & $1 / 1$ & $1 / 1$ & $1 / 2$ & & & & 2 & & 2 & 0.47 \\
\hline 72 & $2 / 2$ & $1 / 1$ & $1 / 1$ & $1 / 1$ & $1 / 1$ & $1 / 3$ & $1 / 2$ & & & & & 3 & 3 & 0.17 \\
\hline 77 & $2 / 2$ & $1 / 2$ & $1 / 1$ & $1 / 1$ & $1 / 1$ & $1 / 3$ & $1 / 2$ & & 3 & & & & 3 & 0.05 \\
\hline 79 & $2 / 2$ & $1 / 3$ & $1 / 1$ & $1 / 2$ & $1 / 1$ & $1 / 2$ & $2 / 2$ & 2 & & & & & 2 & 0.0046 \\
\hline 80 & $2 / 2$ & $2 / 3$ & $1 / 1$ & $1 / 2$ & $1 / 2$ & $1 / 1$ & $1 / 2$ & & & 4 & & & 4 & 0.0004 \\
\hline Sample size & & & & & & & & 19 & 16 & 6 & 32 & 31 & 104 & \\
\hline$G_{\mathrm{O}}{ }^{\mathrm{e}}$ & & & & & & & & & & & & & 16.64 & \\
\hline$G_{E}^{* \mathrm{f}}$ & & & & & & & & & & & & & 38.78 & \\
\hline
\end{tabular}

${ }^{a}$ Multi-locus PCR-RFLP genotype (MRG) designation. MRG designations are not in sequential numeric order.

b Designation and order of PCR marker used to define alleles at each locus.

${ }^{\mathrm{c}}$ Counties where isolates were sampled in North Carolina.

${ }^{\mathrm{d}}$ Expected count of specific MRG according to Hardy-Weinberg expectations.

${ }^{\mathrm{e}} \mathrm{G}_{\mathrm{O}}=1 /\left(\sum \mathrm{p}_{\mathrm{i}}{ }^{2}\right)$, where $\mathrm{p}_{\mathrm{i}}$ is the frequency of a particular multilocus genotype, with $\mathrm{G}_{\mathrm{o}}$ ranging from 1 to $\mathrm{N}$, where $\mathrm{N}$ is the sample size.

${ }^{\mathrm{f}} G_{E}^{*}=1 /(d+(p / N))$, where $d=\Sigma g_{\mathrm{i}}^{2}$ for all genotypes where $\left(g_{i} * N\right) \geq 1$ and $p=\Sigma g_{\mathrm{i}}$ for all the genotypes when $\left(g_{i} * N\right)<1 ; g_{\mathrm{i}}$ is the expected frequency of the multilocus genotype calculated using Hardy-Weinberg expectations.

(HWE tests) for each particular locus (TABLE IV). For all samples, when data were not clone corrected, most loci (at least 5/7) had genotypic counts that did not deviate from Hardy-Weinberg expectations (HWE). Two loci (pP09-Hha I and pP42-Hind III) in the sample from Currituck, one locus (pP83-Hind III) in the sample from Hyde, and one locus (pP46-Hind III) in the sample from Camden showed significant deviation from HWE. After clone correction, all loci had genotypic counts that did not deviate from HWE. 
TABLE III. Genotypic diversity of five population samples of Rhizoctonia solani AG-3 PT in North Carolina

\begin{tabular}{|c|c|c|c|c|c|}
\hline $\begin{array}{c}\text { Source of } \\
\text { isolates }\end{array}$ & Sample size & $\begin{array}{c}\text { Total } \\
\text { number of } \\
\text { genotypes }\end{array}$ & $\begin{array}{c}\text { Number of site } \\
\text { specific } \\
\text { genotypes }\end{array}$ & $\begin{array}{c}\text { Stoddart's } \\
\text { genotypic } \\
\text { diversity }\left(\mathrm{G}_{\mathrm{o}}\right)^{\mathrm{a}}\end{array}$ & $\begin{array}{c}\text { Sample size } \\
\text { corrected } \\
\text { genotypic } \\
\text { diversity }\left(G_{c}\right)^{b}\end{array}$ \\
\hline Washington & 19 & 8 & $3(8)^{c}$ & 6.3333 & 0.3333 \\
\hline Tyrrell & 16 & 6 & $4(6)$ & 4.1290 & 0.2581 \\
\hline Currituck & 6 & 2 & $1(4)$ & 1.8000 & 0.3000 \\
\hline Hyde & 32 & 15 & $11(16)$ & 9.6604 & 0.3019 \\
\hline Camden & 31 & 13 & $7(14)$ & 8.6577 & 0.2793 \\
\hline \multirow[t]{2}{*}{ Overall } & Mean & & & 6.1108 & 0.2945 \\
\hline & Standard deviation & & & 2.8860 & 0.0251 \\
\hline
\end{tabular}

${ }^{a} G_{o}=1 /\left(\Sigma p_{i}{ }^{2}\right)$, where $p_{i}$ is the frequency of a particular multilocus genotype, with $G_{o}$ ranging from 1 to $N$, where $N$ is the sample size.

${ }^{\mathrm{b}} \mathrm{G}_{\mathrm{c}}=\mathrm{G}_{\mathrm{o}} / \mathrm{N}$.

${ }^{c}$ Number of isolates represented by these genotypes.

Population structure.-Analysis of population structure was conducted for both uncorrected and clonecorrected data. Using AMOVA (Analysis of Molecular Variance), overall $\Phi_{\mathrm{ST}}$ between geographic populations was 0.0745 for uncorrected data. When the geographical populations were subdivided into sampling units within geographic populations (counties), subdivision was found to be even slightly higher between sampling units than between geographic populations $\left(\Phi_{\mathrm{ST}}=0.1076\right)$. For clone-corrected data, overall $\Phi_{\mathrm{ST}}$ was -0.0001 between geographic populations. With further hierarchical subdivision of geographical populations into sampling units, the $\Phi_{\mathrm{ST}}$ value was again observed to be slightly higher (0.0111). In general, most of the molecular variation was detected within populations, with very little variation between geographic populations.

Population differentiation and gene flow were also analyzed by estimates of theta $\mathrm{P}\left(\mathrm{F}_{\mathrm{ST}}\right)$ as described by Weir and Cockerham (1984) (TABLE V). Overall F between populations was 0.0741 for uncorrected data, which was significantly greater than zero. Nevertheless, this value of $\mathrm{F}_{\mathrm{ST}}$ also indicates little genetic differentiation among populations. For clone-corrected data overall $\mathrm{F}_{\mathrm{ST}}$ was -0.0009 , which was not significantly different from zero.

Pairwise comparison between geographic populations was performed using estimates of $\mathrm{F}_{\mathrm{ST}}$ equiva-

TABle IV. Patterns of heterozygosity in different samples of Rhizoctonia solani AG-3 PT in North Carolina

\begin{tabular}{|c|c|c|c|c|c|c|}
\hline \multirow[b]{2}{*}{ Population } & \multirow[b]{2}{*}{ Sample type } & \multicolumn{2}{|c|}{ Mean heterozygosity } & \multirow{2}{*}{$\begin{array}{l}\text { No. of loci } \\
\text { in } \mathrm{HWE}^{\mathrm{b}}\end{array}$} & \multirow{2}{*}{$\begin{array}{c}\text { No. of loci with } \\
\text { excess homozygotes }\end{array}$} & \multirow{2}{*}{$\begin{array}{c}\text { No. of loci } \\
\text { with excess } \\
\text { heterozygotes }\end{array}$} \\
\hline & & Expected $^{\mathrm{a}}$ & Observed & & & \\
\hline \multirow[t]{2}{*}{ Washington } & All genotypes ${ }^{c}$ & 0.2392 & 0.2105 & 7 & 0 & 0 \\
\hline & Clone-corrected $^{\mathrm{d}}$ & 0.2714 & 0.2500 & 7 & 0 & 0 \\
\hline \multirow[t]{2}{*}{ Tyrell } & All genotypes & 0.2488 & 0.2946 & 7 & 0 & 0 \\
\hline & Clone-corrected & 0.3333 & 0.3571 & 7 & 0 & 0 \\
\hline \multirow[t]{2}{*}{ Currituck } & All genotypes & 0.3809 & 0.3809 & 5 & $2(\mathrm{pP} 09$ and $\mathrm{pP} 42)$ & 0 \\
\hline & Clone-corrected & 0.4286 & 0.2857 & 7 & 0 & 0 \\
\hline \multirow[t]{2}{*}{ Hyde } & All genotypes & 0.2045 & 0.1875 & 6 & $1(\mathrm{pP} 83)$ & 0 \\
\hline & Clone-corrected & 0.2289 & 0.2286 & 7 & 0 & 0 \\
\hline \multirow[t]{2}{*}{ Camden } & All genotypes & 0.2113 & 0.2073 & 6 & 0 & $1(\mathrm{pP} 46)$ \\
\hline & Clone-corrected & 0.2457 & 0.2527 & 7 & 0 & 0 \\
\hline \multirow[t]{2}{*}{ Total sample } & All genotypes & 0.2570 & 0.2562 & 6 & & \\
\hline & Clone-corrected & 0.3016 & 0.2748 & 7 & & \\
\hline
\end{tabular}

${ }^{a}$ Expected heterozygosity (unbiased) was computed according to Levene (1949) using TFPGA version 1.3 (Miller 1997).

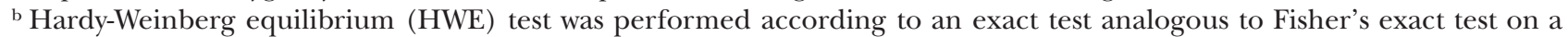
two-by-two contingency table, but extended to a triangular contingency or arbitrary size (Guo and Thompson 1992), using ARLEQUIN 2.000 (chain length: 100 000; dememorization: 1000) (Schneider et al 2000).

c Analysis performed on total data that included all 104 genotypes.

${ }^{\mathrm{d}}$ Clone-corrected data comprising 32 multilocus PCR-RFLP genotypes. 
TABle V. Population differentiation and gene flow of Rhizoctonia solani AG-3 PT in North Carolina

\begin{tabular}{|c|c|c|c|c|}
\hline \multirow[b]{3}{*}{ PCR-RFLP locus } & \multicolumn{4}{|c|}{ Sample Type } \\
\hline & \multicolumn{2}{|c|}{ All isolates ${ }^{\mathrm{a}}$} & \multicolumn{2}{|c|}{ Clone corrected $^{\mathrm{b}}$} \\
\hline & $\mathrm{Nu}^{\mathrm{c}}$ & $\begin{array}{c}\text { theta P } \\
\left(\mathrm{F}_{\mathrm{WC}(\mathrm{ST})}\right)^{\mathrm{d}}\end{array}$ & $\mathrm{Nc}^{\mathrm{c}}$ & $\begin{array}{l}\text { theta } \mathrm{P} \\
\left(\mathrm{F}_{\mathrm{WC}(\mathrm{ST})}\right)\end{array}$ \\
\hline pP09-Hha I & 208 & 0.1420 & 88 & -0.0003 \\
\hline pP42-Hind III & 208 & 0.1009 & 88 & 0.0282 \\
\hline pP45-Hind III & 208 & -0.0116 & 88 & -0.0352 \\
\hline pP46-Hind III & 208 & 0.0648 & 88 & -0.0289 \\
\hline $\mathrm{pP} 47-E c o \mathrm{RV}$ & 208 & 0.2392 & 88 & 0.2355 \\
\hline pP83-Hind III & 208 & -0.0055 & 88 & 0.0227 \\
\hline pP89-Rsa I & 208 & 0.0266 & 88 & -0.0336 \\
\hline Overall & & 0.0741 & & -0.0009 \\
\hline \multirow[t]{2}{*}{ Bootstrapping over loci } & Upper value & 0.1280 & & 0.0499 \\
\hline & Lower value & 0.0290 & & -0.0264 \\
\hline
\end{tabular}

a Analysis performed on total data that included all 104 isolates.

b Clone-corrected data comprising one isolate per multilocus PCR-RFLP genotype; population was retained.

${ }^{\mathrm{c}} \mathrm{N}=$ sample size of alleles for uncorrected $(\mathrm{Nu})$ and clone-corrected data $(\mathrm{Nc})$.

${ }^{\mathrm{d}} \mathrm{F}$ statistics were estimated as in Weir and Cockerman (1984) using GDA version 1.0 (d15) (Lewis and Zaykin 2000).

lents (pairwise $\Phi_{\mathrm{ST}}$ values) and Nei's unbiased genetic distances (D), for both uncorrected and clone-corrected data (TABLE VI). Pairwise $\Phi_{\mathrm{ST}}$ values were significantly greater than zero, which would indicate population differentiation, only for uncorrected data. For example, the population from Washington was significantly different from Tyrrell and Currituck and very similar to Hyde and Camden county populations. For clone-corrected data, however, there was no indication of population differentiation considering both pairwise $\Phi_{\mathrm{ST}}$ values and D.

HWE test for association of alleles within loci and exact test for linkage disequilibrium between pairs of loci.Based on the lack of geographic subdivision, all MRG data were pooled into a single data set (for both uncorrected and clone-corrected samples) to test for HWE (TABLE VII) and composite linkage disequilibrium (TABLE VIII) between all pairs of loci.

The results from the likelihood ratio test $\left(\mathrm{G}^{2}\right)$ and the exact test analogous to Fisher's indicated genotypic proportions similar to HWE proportions at all seven loci (for clone-corrected data) and for six loci considering the uncorrected sample. For uncorrected data, only the locus pP09-Hha I showed proportions of genotypic counts that deviated from HWE. Overall, for uncorrected data, most pairs of loci were in genotypic disequilibrium $(13 / 21)$. However, for clone-corrected data, the exact test for linkage disequilibrium was not significant for all pairs of loci.

\section{DISCUSSION}

This study describes a PCR-RFLP method for genotyping isolates of $R$. solani AG-3 PT. We employed a combination of two strategies for development of codominant markers as proposed by Rosewich et al (1999) and Xu et al (1999). The method established here enables unambiguous scoring of genotypes of

TABle VI. Population pairwise $\Phi_{\mathrm{ST}}{ }^{\mathrm{a}}$ of Rhizoctonia solani AG-3 PT isolates collected from five commercial potato fields in North Carolina, for clone-corrected data (above diagonal) and total data (below diagonal)

\begin{tabular}{|c|c|c|c|c|c|}
\hline County & Washington & Tyrrell & Currituck & Hyde & Camden \\
\hline Washington & - & -0.0270 & -0.0063 & -0.0192 & -0.0179 \\
\hline Tyrrell & $0.0730 * *$ & - & -0.0933 & 0.0186 & 0.0035 \\
\hline Currituck & $0.2107 * * *$ & $0.1232 *$ & - & 0.0656 & 0.0452 \\
\hline Hyde & 0.0050 & $0.1057 * * *$ & $0.2949 * * *$ & - & 0.0089 \\
\hline Camden & 0.0229 & $0.0320 *$ & $0.2572 * * *$ & 0.0146 & - \\
\hline
\end{tabular}

a Population pairwise $\Phi_{\mathrm{ST}}$ was calculated using ARLEQUIN ver 2.000 (Schneider et al 2000). Asterisks indicate significance of $\mathrm{P}$ values at $\mathrm{P}<0.05(*), \mathrm{P}<0.01(* *)$ and $\mathrm{P}<0.001(* * *)$ leading to values of $\Phi_{\mathrm{ST}}$ larger than or equal to the observed value when permuting multilocus PCR-RFLP genotypes between populations (1000 permutations were performed). 
TABLE VII. Test for Hardy-Weinberg equilibrium for multilocus PCR-RFLP genotypes of Rhizoctonia solani AG-3 PT

\begin{tabular}{|c|c|c|c|c|}
\hline PCR-RFLP locus & Sample type & $\mathrm{G}^{2 \mathrm{a}}$ & $\mathrm{P}^{\mathrm{b}}$ & Prob. ${ }^{c}$ \\
\hline \multirow[t]{2}{*}{ pP09-Hha I } & All genotypes ${ }^{\mathrm{d}}$ & 5.5963 & $0.0180^{* \mathrm{f}}$ & 0.0220 \\
\hline & Clone-corrected $^{\mathrm{e}}$ & 2.6336 & 0.1046 & 0.1647 \\
\hline \multirow[t]{2}{*}{ pP42-Hind III } & All genotypes & 6.6992 & 0.0719 & 0.0978 \\
\hline & Clone-corrected & 1.6713 & 0.6433 & 1.0000 \\
\hline \multirow[t]{2}{*}{ pP45-Hind III } & All genotypes & 0.0000 & 1.0000 & 1.0000 \\
\hline & Clone-corrected & 0.0000 & 1.0000 & 1.0000 \\
\hline \multirow[t]{2}{*}{ pP46-Hind III } & All genotypes & 2.2509 & 0.1335 & 0.5944 \\
\hline & Clone-corrected & 2.0918 & 0.1400 & 0.5546 \\
\hline \multirow[t]{2}{*}{$\mathrm{pP} 47-E c o \mathrm{RV}$} & All genotypes & 0.2090 & 0.6476 & 1.0000 \\
\hline & Clone-corrected & 0.2001 & 0.6546 & 1.0000 \\
\hline \multirow[t]{2}{*}{ pP83-Hind III } & All genotypes & 5.2690 & 0.1531 & 0.0738 \\
\hline & Clone-corrected & 0.5581 & 0.9060 & 0.8412 \\
\hline \multirow[t]{2}{*}{ pP89-Rsa I } & All genotypes & 0.1950 & 0.6588 & 0.6934 \\
\hline & Clone-corrected & 3.8240 & 0.5363 & 0.7249 \\
\hline
\end{tabular}

a Log likelihood statistic $\left(\mathrm{G}^{2}\right)$ calculated using POPGENE (Yeh et al 1997).

b Probability of $\mathrm{G}^{2}$.

${ }^{c}$ Exact test analogous to Fisher's exact test on a two-by-two contingency table, but extended to a triangular contingency or arbitrary size (Guo and Thompson 1992), using ARLEQUIN 2.000 (chain length: 100 000; dememorization: 1000) (Schneider et al 2000).

d Analysis performed on total data that included all 104 isolates.

e Clone-corrected data comprising 32 multilocus PCR-RFLP genotypes.

${ }^{\mathrm{f}}$ Asterisk denotes significant $\mathrm{P}$ value at $\mathrm{P}<0.05(*)$, indicating significant deviation from Hardy-Weinberg equilibrium.

isolates of $R$. solani AG-3 PT by allowing the distinction between homozygotes and heterozygotes. The PCR-RFLP method is also efficient, as only small amounts of DNA are required as starting material. Consistent with the heterokaryotic nature of $R$. solani, which has been confirmed by a similar molecular typing method (Rosewich et al 1999), every isolate had one or more heterozygous loci (TABLE II).

During the process of screening, four of the seven PCR-RFLP markers used for genotyping $R$. solani AG3 PT (pP42, pP46, pP47 and pP89) also amplified genomic DNA from $R$. solani AG-3 TB, a pathogen of tobacco. Except for marker pP42, none of the alleles present in the sample of 20 tobacco isolates of $R$. solani AG-3 TB were shared with the potato sample (data not shown). Our findings corroborate previous information that populations of $R$. solani AG-3 are subdivided by host specialization (Ceresini et al 2001, Kuninaga et al 1997, Kuninaga et al 2000, Ogoshi 1987, Shew and Melton 1995, Stevens Johnk et al 1993). These four genetic markers could have potential applicability for phylogenetic analysis within $R$.

TABLE VIII. Exact tests for linkage disequilibrium ${ }^{a}$ among pairs of individual PCR-RFLP loci based on 32 multilocus genotypes

\begin{tabular}{|c|c|c|c|c|c|c|c|}
\hline PCR-RFLP locus & pP09 Hha I & pP42 Hind III & pP45 Hind III & pP46 Hind III & pP47 Eco RV & pP83 Hind III & pP89 Rsa I \\
\hline pP09 Hha I & - & $0.6794^{\mathrm{b}}$ & 1.0000 & 0.2984 & 0.9692 & 0.0938 & 0.7972 \\
\hline pP42 Hind III & 0.0103 & - & 0.5867 & 0.3298 & 0.0643 & 0.1608 & 0.8782 \\
\hline pP45 Hind III & 0.9999 & 0.4509 & - & 1.0000 & 1.0000 & 1.0000 & 0.9812 \\
\hline pP46 Hind III & 0.0180 & 0.00002 & 0.2021 & - & 0.5768 & 0.4756 & 0.4403 \\
\hline pP47 Eco RV & 0.0662 & 0.0006 & 0.0689 & 0.0077 & - & 0.8246 & 0.4847 \\
\hline pP83 Hind III & 0.0001 & 0.1546 & 0.2497 & 0.0086 & 0.6455 & - & 0.7112 \\
\hline pP89 Rsa I & 0.4422 & 0.2082 & 0.7008 & 0.0453 & 0.2794 & 0.2875 & 一 \\
\hline
\end{tabular}

a Linkage disequilibrium between pairs of loci was assessed using a exact test analogous to Fisher's exact test (Slatkin 1994, Slatkin and Excoffier 1996). The calculations were performed using ARLEQUIN 2.000 (number of permutations = 100 172; number of initial conditions for E.M. = 10) (Schneider et al 2000).

${ }^{\text {b }} \mathrm{P}$ values for the exact test of association between alleles conditional to the allelic counts. Numbers above the diagonal are probabilities of association analyzed from the clone-corrected sample consisting of 32 unique multilocus PCR-RFLP genotypes. Numbers below the diagonal are probabilities of association analyzed from the total sample consisting of all 104 isolates. Significant P values are indicated in bold. 
solani AG-3 as they were shown to be conserved enough to amplify genes across AG-3 PT and AG-3 $\mathrm{TB}$, two genetically distinct subgroups of AG-3.

The first objective of this study was to determine the extent of genetic differentiation among populations of $R$. solani AG-3 PT and make inferences about gene flow and population subdivision. The allelic information from the seven single locus PCR-RFLP markers allowed us to group 104 isolates of $R$. solani AG-3 PT into 32 MRG. Gene flow was high, even though relatively few MRG were shared among localities. The overall $\Phi_{\mathrm{ST}}$ between geographic populations was 0.0745 for total data. When data were subdivided into sampling locations (plots) within a field, subdivision was found to be even slightly higher between sampling units than between geographic populations $\left(\Phi_{\mathrm{ST}}=0.1076\right)$. However, using clone-corrected data, $\Phi_{\mathrm{ST}}$ and $\mathrm{F}_{\mathrm{ST}}$ estimates were essentially zero. In addition, for clone-corrected data, all pairwise $\Phi_{\mathrm{ST}}$ values were not significant at $5 \%$, and Nei's genetic distance (D) indicated no differentiation between populations.

Our results support the existence of a mechanism that ensures efficient long distance dispersal of genotypes between geographic populations. Recent analysis of the contribution of tuber-borne genotypes to the overall population of $R$. solani AG-3 PT present in potato fields of North Carolina provided evidence on how tuber-borne inoculum introduced every year affects population structure of the pathogen. High levels of genetic diversity were detected in introduced potato tubers from Canada (New Brunswick), Maine, and Wisconsin (50 different genotypes among a total sample of 58 isolates) (Ceresini 2000). Nevertheless, seven of these genotypes were among the most frequent genotypes observed in North Carolina fields (Ceresini 2000).

A similar lack of population structure was found for $R$. solani AG-1-IA from rice in Texas (Rosewich et al 1999). The authors characterized seven co-dominant RFLP loci for 182 AG-1 IA isolates in Texas rice fields and found 36 different multilocus genotypes. As there was no evidence for population subdivision, all isolates from the rice growing areas in Texas were considered to be part of one single population of $R$. solani AG-1 IA. Considering the similar observations of lack of population structure within $R$. solani AG-3 PT, we also pooled all multilocus PCR-RFLP genotypes into one single data set for further analysis of HWE and linkage disequilibrium.

The other specific question addressed in this study was: Does multilocus genetic diversity analysis support a sexual structure in local populations of $R$. solani AG-3 PT? Several studies have provided information about the structure of $R$. solani populations on wheat in Australia and rice in Texas. For example, MacNish et al (1997) found an association of anastomosis reaction type with allozymes and an overrepresentation of certain phenotypes, which was considered evidence for clonality. Evidence for clonality was also demonstrated for $R$. solani AG-1-IA through findings of repeated recovery of genotypes in the same and different rice field (Rosewich et al 1999).

To answer the question on population structure of $R$. solani AG-3 PT from potato, we considered the main effects of asexual reproduction on the pathogen population. The first major effect of asexual reproduction is the production of fewer recombinant genotypes, which decreases genotypic diversity. In this study the hypothesis of clonality was partially supported in that at least three of the population samples from potato shared the most common multilocus genotypes (MRG 1, 3 and 48) (TABLE II). In addition, observed counts for MRG 1, MRG 3, or MRG 48 were much higher than the expected counts derived under the hypothesis of panmixia (Stoddart and Taylor 1988). The higher frequency of these genotypes in potato samples may be the consequence of asexual reproduction, since all three MRGs were also found on seed potato tubers introduced from Maine into NC (Ceresini 2000). In addition, if populations of $R$. solani AG-3 PT were totally panmictic, the observed genotypic diversity would be similar to the expected value under panmixia (Stoddart 1983). Our results indicated that the overall genotypic diversity $\left(G_{o}\right.$ for uncorrected data $\left.=16.64\right)$ was considerably smaller than the expected value under panmixia $\left(G_{E}^{*}=38.78\right)$ (TABLE II), supporting clonality. The clonal reproduction of $R$. solani AG-3 PT via mycelia or sclerotia provides a mechanism for a local collection of clones to predominate within a much larger recombining population of the pathogen on potato. However, the biological features of these asexual structures (mycelia and scletoria), especially the mode of dissemination, will influence the scale and intensity of clonal spread (Taylor et al 1999). A clonal structure for a population of $R$. solani AG-3 PT in South Australia could not be rejected because one DNA fingerprint pattern represented $30 \%$ of the isolates tested (Balali et al 1996).

The repeated occurrence of genotypes of $R$. solani AG-3 PT clearly suggests that populations are not only randomly mating (Milgroom 1996). However, the multiple occurrence of genotypes can be a confounding factor in the analyses of population structure of this potato pathogen. Therefore, the approach of analyzing the population structure of $R$. solani AG-3 PT considering only one representative of each multilocus genotype is appropriate. This approach has been recommended for making inferenc- 
es about recombination in other populations of plant pathogenic fungi (Liu et al 1996, McDonald et al 1994, Rosewich et al 1999).

The second major effect of recombination on population structure is the random association of alleles both within (HWE) and between loci (linkage equilibrium). When all genotypes were included in the analysis, only one locus (pP09 Hha I) was not in HWE. In addition, linkage disequilibrium was detected for eight pairs of loci. However, for clone-corrected data, both tests for HWE indicated that all loci were in equilibrium and no linkage disequilibrium was detected for any pair of loci. This emphasizes the importance of using clone-corrected data to better understand aspects of reproduction that contribute to population structure (McDonald et al 1994, Rosewich et al 1999). Comparatively, analyses of the population structure of $R$. solani AG-1-IA from rice indicated that four of seven RFLP loci were in HWE and only one of all possible pairs of loci was in linkage disequilibrium, which indicated that recombination was occurring (Rosewich et al 1999).

At the extremes of models of population structure, populations may be panmictic or strictly clonal. An intermediate model was proposed by Maynard Smith et al (1993) for bacterial pathogens. This model may also be appropriate for many fungal plant pathogens that have annual sexual cycles and asexual phases. This model is characterized by frequent recombination and by the occurrence of one or a few successful individual genotypes that reproduce clonally and increase to high frequencies. Differences in fitness among genotypes expressed in the asexual phase could be responsible for the prevalence of certain genotypes. Our observations support a model of population structure for $R$. solani AG-3 PT that includes both clonality and recombination.

This study provided initial information on population genetics of $R$. solani AG-3 PT in NC. Further studies are needed to elucidate the magnitude of recombination in populations of $R$. solani AG-3 PT. In addition, increased sampling is needed to maximize genotypic diversity and enhance the power of statistical tests to infer population genetic processes. Increased resolution to infer population structure also may be achieved by the examination of additional genetic loci to ascertain that MRGs identified in this study actually represent clones.

Consideration also should be given to the elucidation of the role of other evolutionary processes that could cause linkage disequilibrium in populations of $R$. solani AG-3 PT, such as gene flow or migration. Gene flow can cause gametic disequilibrium by the immigration of individuals from populations with different allele frequencies (Milgroom 1996).
Future research also should examine populations of $R$. solani AG-3 PT from the northern United States (Wisconsin and Maine) and eastern Canada, as these areas are responsible for the production of most of the seed potatoes imported into eastern North Carolina.

\section{ACKNOWLEDGMENTS}

We thank Dr. H. Corby Kistler (USDA/ARS, Cereal Diseases Lab, St. Paul, Minnesota), Steven Leath, (USDA/ARS, Dept. of Plant Pathology, NCSU), Tim James, and Daniel Snyder (Dept. of Biology, Duke University,). Special thanks for Pamela Puryear (Tobacco Literature Service, NCSU) for locating literature. This research was supported in part with a research assistantship from $\mathrm{CNPq}$ (Conselho Nacional deDesenvolvimento Científico e Tecnológico)—Brasília, DF, Brazil (200873/92-8) and with a graduate student fellowship and E.E. Butler travel award from The Mycological Society of America awarded to PC. A leave of absence was also granted to PC by UNESP (Universidade Estadual Paulista "Júlio de Mesquita Filho"), Ilha Solteira, São Paulo, Brazil, for attending the Ph.D. program on Plant Pathology at North Carolina State University. Special thanks to Drs. Ana Maria R. Cassiolato and Marli F. Stradioto Papa for assuming the teaching responsibilities of PC at UNESP during his absence.

\section{LITERATURE CITED}

Balali GR, Whisson DL, Scott ES, Neate SM. 1996. DNA fingerprinting probe specific to isolates of Rhizoctonia solani AG-3. Mycol Res 100:467-470.

Carling DE, Leiner RH, Westphale PC. 1989. Symptoms, signs, and yield reduction associated with rhizoctonia disease of potato induced by tuberborne inoculum of Rhizoctonia solani AG-3. Am Potato J 66:693-702.

Ceresini PC. 2000. Population biology and genetics of Rhizoctonia solani anastomosis group 3 (AG-3). Dept. of Plant Pathology, North Carolina State University. [PhD Dissertation]. 89 p.

— diversity of Rhizoctonia solani anastomosis AG-3 from potato and tobacco in North Carolina. Mycologia 94: (in press).

Cubeta MA, Vilgalys R. 1997. Population biology of the Rhizoctonia solani complex. Phytopathology 87:480-484. 2000. Rhizoctonia. In. Lederberg J, ed. Encyclopedia of microbiology Vol. 4. San Diego: Academic Press. pp. 109-116.

Excoffier L, Smouse P, Quattro J. 1992. Analysis of molecular variance inferred from metric distances among DNA haplotypes: application to human mitochondrial restriction data. Genetics 131:479-491.

Guo SW, Thompson EA. 1992. Performing the exact test of Hardy-Weinberg proportions for multiple alleles. Biometrics 48:361-372.

Gutierrez WA, Shew HD, Melton TA. 1997. Sources of inoculum and management for Rhizoctonia solani damp- 
ing-off on tobacco transplants under greenhouse conditions. Plant Disease 81:64-66.

Hartl DL, Clark AG. 1997. Principles of population genetics. 3rd ed. Sunderland, Massachusetts: Sinauer. 542 p.

Herr LJ, Roberts DL. 1980. Characterization of Rhizoctonia solani populations obtained from sugarbeet fields with differing soil textures. Phytopathology 70:476-480.

Karl SA, Avise JC. 1993. PCR-based assays of Mendelian polymorphisms from anonymous single copy nuclear DNA: techniques and applications for population genetics. Mol Biol and Evol 10:342-361.

Kuninaga S, Natsuaki T, Takeuchi T, Yokosawa R. 1997. Sequence variation of the rDNA ITS regions within and between anastomosis groups in Rhizoctonia solani. Curr Genetics 32:237-243.

— Carling DE, Takeuchi T, Yokosawa R. 2000. Comparison of rDNA-ITS sequences from potato and tobacco strains in Rhizoctonia solani AG-3. J Gen Plant Pathol 66:2-11.

Laroche JP, Jabaji-Hare SH, Charest PM. 1992. Differentiation of two anastomosis groups of Rhizoctonia solani by isozyme analysis. Phytopathology 82:1387-1393.

Levene H. 1949. On a matching problem arising in Genetics. Ann Math Stat 20:91-94.

Lewis PO, Zaykin D. 2000. Genetic data analysis: computer program for the analysis of allelic data. Version 1.0 (d15). Free program distributed by the authors over the internet from the GDA Home Page at http:// alleyn.eeb.uconn.edu/gda

Liu Y-C, Cortesi P, Double ML, McDonald WL, Milgroom MG. 1996. Diversity and multilocus genetic structure in populations of Cryphonectria parasitica. Phytopathology 86:1344-1351.

Liu ZL, Domier LL, Sinclair JB. 1993. ISG-specific ribosomal DNA polymorphism of the Rhizoctonia solani species complex. Mycologia 85:795-800.

- Sinclair JB. 1992. Genetic diversity of Rhizoctonia solani anastomosis group 2. Phytopathology 82:778-787.

McDonald BA, Miles J, Nelson LR, Pettway RE. 1994. Genetic variability in nuclear DNA in field populations of Stagonospora nodorum. Phytopathology 84:250-255.

MacNish GC, Carling DE, Brainard KA. 1997. Relationship of microscopic and macroscopic vegetative reactions in Rhizoctonia solani and the occurrence of vegetatively compatible populations (VCPs) in AG-8. Mycol Res 101:61-68.

Martin B. 1987. Rapid tentative identification of Rhizoctonia spp. associated with diseased turfgrasses. Plant Dis 71: 47-49.

Maynard Smith J, Smith NH, O'Rourke M, Spratt BG. 1993. How clonal are bacteria? Proc Natl Acad Sci USA 90: 4384-4388.

Milgroom MG. 1996. Recombination and the multilocus structure of fungal populations. Annu Rev Phytopathol 34:457-477.

Miller MP. 1997. Tools for Population Genetic Analyses (TFPGA): a Windows ${ }^{\circledast}$ program for analysis of allozyme and molecular population genetic data. Version 1.3. Free program distributed by the author over the Internet from the website http://herb.bio.nau.edu/ miller
Nei M. 1978. Estimation of average heterozygosity and genetic distance from a smaller number of individuals. Genetics 89:583-590.

- 1987. Molecular evolutionary genetics. New York: Columbia University Press. 512 p.

Ogoshi A. 1987. Ecology and pathogenicity of anastomosis and intraspecific groups of Rhizoctonia solani Kühn. Annu Rev Phytopathol 25:125-143.

Rosewich UL, Pettway RE, McDonald BA, Kistler HC. 1999. High levels of gene flow and heterozygote excess characterize Rhizoctonia solani AG-1 IA (Thanatephorus cucumeris) from Texas. Fungal Genet Biol 28:148-159.

Schneider S, Roeslli D, Excoffier L. 2000. ARLEQUIN: a software for population genetics data analysis. Version 2.000. Switzerland: University of Geneva. Free program distributed by the authors over the Internet from the website http://anthro.unige.ch/arlequin

Shew HD, Melton TA. 1995. Target spot of tobacco. Plant Dis 79:6-11.

Slatkin M. 1994. Linkage disequilibrium in growing and stable populations. Genetics 137:331-336

— um in genotypic data using EM algorithm. Heredity 76 : 377-383.

Stevens Johnk J, Jones RK, Shew HD, Carling DE. 1993. Characterization of populations of Rhizoctonia solani AG-3 from potato and tobacco. Phytopathology 83:854858.

Stoddart JA. 1983. A genotypic diversity measure. J Hered 74:489-490.

— , Taylor JF. 1988. Genotypic diversity: estimation and prediction in samples. Genetics 118:705-711.

Taylor JW, Jacobson DJ, Fisher MC. 1999. The evolution of asexual fungi: reproduction, speciation and classification. Annu Rev Phytopathol 37:197-246.

Vilgalys R, Cubeta MA. 1994. Molecular systematics and population biology of Rhizoctonia. Annu Rev Phytopathol 32:135-155.

$\longrightarrow$, Gonzalez D. 1990. Ribosomal DNA restriction fragment length polymorphisms in Rhizoctonia solani, Phytopathology 80:151-158.

Weir BS. 1996. Genetic data analysis. 2nd. ed. Sunderland, Massachusetts: Sinauer. 445 p.

- Cockerham CC. 1984. Estimating F-statistics for the analysis of population structure. Evolution 38:13581370.

Xu J, Mitchell T, Vilgalys R. 1999. PCR-restriction fragment length polymorphism (RFLP) analyses reveal both extensive clonality and local genetic differences in Candida albicans. Mol Ecol 8:59-73.

Yeh FC, Yang R-C, Boyle TBJ, Ye ZH, Mao JX. 1997. POPGENE: microsoft Windows -based freeware for population genetic analysis. Version 1.32. Canada: University of Alberta and Centre for International Forestry Research. Free program distributed by the authors over the Internet from the website at http://www.ualberta. ca/ fyeh/fyeh

Zaykin D, Zhivotovsky L, Weir BS. 1995. Exact tests for association between alleles at arbitrary numbers of loci. Genetica 96:169-178. 